\title{
Motivation behind Bicycling Habit in Sylhet City of Bangladesh
}

\section{Taharat Nawaz}

Department of Business Administration, North East University Bangladesh, Sylhet, BANGLADESH

\begin{abstract}
The study was conducted in the Sylhet City of Bangladesh. The purpose of the study is to explore the motivational factors behind bicycling habit in Sylhet. Analysis of secondary data and a focus group session with pioneer cyclists contributed in obtaining variables for the study. A sample of 100 respondents of Sylhet participated in this study. Judgemental sampling technique has been used to obtain data from self-administered structured questionnaire. Statistical analyses used in the survey are Exploratory Factor Analysis to identify factors and Frequencies for analysing demographic variables. The result of the study explains four factors. Findings show that the favorable factors towards cycling are Factor 1, Health and Factor 2, Convenience. Factor 3, Weather and Factor 4 Security are deterrent factors in cycling. The research findings provide wider scope for urban planning and catering of promotional strategies by bicycle marketers. In an overly populated country like Bangladesh, bicycling can give us a congestion free road and the plociy makers can grab this opportunity to make a better strategy for urban planning.
\end{abstract}

Keywords: Bicycling habit, Sylhet, Exploratory Factor Analysis JEL Classification Code: M31

\section{INTRODUCTION}

Motivation is the driving force within individuals that impels them to action. The specific goals that consumers wish to achieve and the courses of action they take to attain these goals are selected on the basis of their thinking process and previous learning. Therefore, marketers must view motivation as the force that induces consumption and through consumption experiences, the process of consumer learning (Schiffman and Kanuk, 2004).

Motivational research attempts to discover underlying feelings, attitudes and emotions concerning product, service or brand use. Since motivational research often reveals unsuspected consumer motivations concerning product or brand usage, its principal use today is in the development of new ideas that can penetrate the consumer's conscious awareness by appealing to unrecognized needs. (Schiffman and Kanuk, 2004)

Since inception, the two-wheel human powered driving machine known as bicycle has taken a distinctive place in the mode of transportations. Despite the presence of automobiles and other vehicles, bicycle is still popular among many groups all over the world. The primary use of bicycle as a mode of transportation is now shifting its focus and gradually moving towards exploring multiple benefits factors.

In some areas of the world, governments are actively participating in promoting bicycling among the citizens whereas individual efforts are taken to promote bicycling in other areas. Cycling revolution in Copenhagen of Denmark happened because of the active participation of government and the enthusiastic cyclists. As reported by the UCI official website (2014), International Cycling Union has awarded Copenhagen as the first bike city in year 2007. Among world's most bike friendly cities are Amsterdam, Berlin, Dublin, Tokyo, Montreal, Hamburg and Paris. Following the cycling trend in Europe, U.S.A and some Asian countries, cycling revolution has started in Bangladesh in year 2011. The pioneer of cycling in Bangladesh is a young Information Technology Professional. Bdcyclists- the first cyclists group in Bangladesh is established by the same individual. Initially, the usage was limited within the professionals for commuting purpose. With the rapid acceptance of bicycle as an independent mode of communication, it is now getting acceptance in the young generation for both commuting and recreational purposes.

According to the official webpage of Bdcyclist (2014), the number of registered cyclists in this group is above 33,000. The capital was the first to embrace cycling at a faster rate. But the trend is spreading towards other cities as well. A very popular riding venue for the cyclist is Sylhet. The well-paved road, tea garden and hilly track of this part of the country offer exclusive riding experience to many cyclists. There are growing numbers of cyclists groups in the town. Aside of commuting to work place, members of the groups arrange for weekly events, events on special occasion, beginner's lesson and adventure trips. A different type of project organized by Bdcyclists group is 64 Good Acts. The goal of this project is to ride 64 districts of Bangladesh and help out a school, family or needy people (Bdcyclists, 2014). Cyclist groups in Sylhet region also organize occasional charity projects. 
This newest cycling trend in Bangladesh has not only made people re-think about their choice of transportation but also created a boom in the cycling business. There has been a rapid growth in the number of cycling shop around the country in recent years. Since most of the buyers are younger in age, demand for stylish featured cycles is enhancing. Along with bicycle, sellers are offering bicycle accessories, cleaning service, repair service(Alam, 2013). Growing popularity of cycling in other regions of the world have interested many researchers to learn more about the demographic, economic and other underlying reasons for cycling.

Unlike most vigorous physical activities engaged in for health-related or recreational purposes, activities such as walking and cycling can be done for multiple purposes, likely making them more susceptible to environmental influence. Walking and cycling can be done for leisure, recreation, or exercise; for occupational purposes; and for basic transportation, including shopping and going to work. (Saelens, Sallis and Frank, 2003) Sener, Eluru and Bhatt (2009) focused on use of bicycle to address health problems such as obesity caused by physically inactive lifestyles. They also identified that those who bicycle to work are quite young, and these same individuals are more environmentally conscious, because of which they appear to use the bicycle for all purposes. The decision to cycle is rarely made in a private bubble without external influence. It usually depends on an interaction between individual desires and abilities, social influences and the physical environment (Enabling Change, 2011).

Technical improvement has made modern bicycles efficient and convenient to use. There is no pollution from bicycle, they are silent, economical, discreet, accessible to all members of the family and above all, a bike is faster than a car over short urban distances.The European Union is focusing on labelling private cars as regards the $\mathrm{CO} 2$ they produce and a fiscal policy which will favor a greater decrease in $\mathrm{CO} 2$ in the future. Agreement has been reached between the European Union and motor manufacturers to reduce the number of vehicles sold in Europe.The British Medical Association, (BMA)'s report, advocates stepping up cycling routes and parking areas for bicycle, cutting down traffic, reducing speed and promoting an awareness campaign aimed at making drivers more respectful of cyclists.In the town of Courtrai (Belgium), the town council is paying special attention to the cycling routes(Dekoster and Schollaert, 1999).

The primary inspiration behind the research is the growing number of cyclists in this city. To the knowledge of the researcher, no earlier research was conducted on this topic within the country. Limited number of research works can be traced back to U.S.A and European Countries. Therefore, this topic is selected to understand various benefit factors associated with cycling. The constant change in climate and other environmental issues are big concern for our country right now. The research is initiated to justify potential of bicycling habit as a tool to reduce the consequences of climate change in Bangladesh. The findings can be helpful to the marketers to better segment the bicycle market based on the underlying motivation for bicycling. The result can help policy makers to identify bicycling as a probable solution for traffic congestion and pollution. The findings can be helpful in individual level to adopt cycling for health benefits and cost reduction purpose.

\section{OBJectives}

The research has been undertaken to identify key factors behind the growing adoption of bicycling as a habit among the people of urban areas of Sylhet. The study has following objectives:

- To identify factors responsible for motivation behind bicycling.

- To find outthe deterrent factors faced by the cyclists.

- To assess future potentials of bicycling in Bangladesh.

\section{METHODOLOGY}

Sylhet city is the study area of this research. Population of the study is comprised of people aged above 15 who are independent to choose cycling as their mode of transportation. Judgmental sampling technique was used in this regard. The study was executed among 100 respondents who were pre-screened. A self-administered structured questionnaire composed of itemized rating scale was applied. The 5 point Likert scale $(5=$ Strongly Agree; 4=Agree; 3=Neither Agree nor Disagree; 2= Disagree; $1=$ Strongly Disagree) was developed to measure attributes affecting the choice of cycling. Appropriate statistical analyses such as Frequencies and Exploratory Factor Analysis has been used to serve the purpose of the research. SPSS software was used to conduct these analyses. Relevant secondary data has been collected from research reports, newspapers, web sites and web pages of the cyclist groups of Bangladesh. A focus group interview with the pioneer cyclists in Sylhet was organized to obtain variables for the study.

\section{Data Analysis}

A number of cyclist groups currently co-exist in Sylhet. The websites of Sustian Cyclists and Sylhet Cycling Community (2015) indicate the number of members in these top two cycling group is 7,902 at present. Among the number of respondents participated in the survey, 93\% are male and $7 \%$ are female. Both secondary and primary data analysis show the fact that number of female participants is significantly poor in sports or other physical activities in this part of Asia. The focus group session with the cyclists indicated that the conservative culture and value system in a male-dominating society are the primary hindrances in poor female participants in cycling. 
Data have been collected from separate age group. $54 \%$ of the respondents belong to the age group 21-30. Respondents below age 20 are $30 \%$; only $4 \%$ of the respondents are above 40 . Among these respondents, $64 \%$ are students, and $28 \%$ are service holders. Cyclists who are engaged in businesses are $8 \%$. Income level is below 15000 for $19 \%$ respondents. Only 5\% of the respondents have an income level above 45000. 49\% respondents have no income at all. The underlying reason for this no income group could be associated with the occupation of the respondents where the findings reveal majority of the cyclists are students. Thus, the demographic data of the respondents show that the majority of the cyclists in the urban area of Sylhet are male students who have no earning source.

Survey indicates $88 \%$ of the respondents belong to these cycling clubs whereas the rest are self-riders.

Table 1: Numbers of Cyclists members in Bicycling Clubs

\begin{tabular}{|l|r|r|r|r|}
\hline Name of the clubs & Frequency & Percent & $\begin{array}{r}\text { Valid } \\
\text { Percent }\end{array}$ & $\begin{array}{c}\text { Cumulative } \\
\text { Percent }\end{array}$ \\
\hline Sylhet Cycling Community & 42 & 42.0 & 47.7 & 47.7 \\
\hline Team CLE & 16 & 16.0 & 18.2 & 65.9 \\
\hline Sustian Cyclist & 19 & 19.0 & 21.6 & 87.5 \\
\hline Roking Riderz & 6 & 6.0 & 6.8 & 94.3 \\
\hline NEMC Cycling Society & 5 & 5.0 & 5.7 & 100.0 \\
\hline Missing & 12 & 12.0 & & \\
\hline Total & 100 & 100.0 & & \\
\hline
\end{tabular}

Respondents' usage of various kinds of vehicle for daily commuting generated interesting scenario. $38 \%$ respondents argued the use of Rickshaw, CNG and Auto Rickshaw for $25-40 \%$ of their total commuting. Bicycle is used by $51 \%$ respondents for more than $40 \%$ total commuting. The usage rate of other types of vehicle namely Human Hollar, Town Bus, Personal Car and Personal Motorbike is low.The purpose of bicycling shows different dimension. In $75-100 \%$ of total commuting, $42 \%$ of the respondents use bicycle for special situation (i.e. Hartal/ Strike), $40 \%$ use it for recreational purpose (i.e. joy riding). Use of bicycling for organizational purpose (i.e. Bicycling Club) are $37 \%$ where $34 \%$ respondent use it for commuting to work place and special occasion (i.e. National days, Rallies). For casual purpose (i.e. Attending Functions, Seeing Friends) and for Exercising, bicycle users are 31\% and $29 \%$ respectively.

Since bicycling culture is a comparatively newer concept in Bangladesh, little are known about the underlying reasons behind this culture. Therefore, Exploratory Factor Analysis has been used in this research to reduce the number of variables into common factors. Malhotra and Dash(2010) identifiesfactor analysis is a general name denoting a class of procedures primarily used for data reduction and summarization. They also states that in marketing research, there may be a large number of variables, most of which are correlated and which must be reduced to a manageable level.

For better organization of the study, several steps have been undertaken. Step one involves determining number of factors to be extracted for analysis based on scree plot and percentage of variances explained by each factor. Factors above the turning point in the scree plot are chosen for the survey. To qualify for retention, desired cumulative variances explained by factors have been pre-specified at $60 \%$.Step two involves rotation of retained factors for further interpretation. Orthogonal rotation technique using varimax rotation has been selected for this step.

Table 2: KMO and Bartlett's Test

\begin{tabular}{|c|r|}
\hline Kaiser-Meyer-Olkin Measure of Sampling Adequacy. & .698 \\
Bartlett's Test of Sphericity & Approx. Chi-Square \\
df & 1074.904 \\
Sig. & 210 \\
\hline
\end{tabular}

Table 2 is a measurement of KMO and Bartlett's Test. The KMO statistics is .698 which is above the standard value 0.5 . Bartlett's Test of Sphericity is significant at the level $(\mathrm{P}=.000)$. These results indicate data are appropriate for factor analysis.

Table 3: Total Variance Explained

\begin{tabular}{|c|c|c|c|c|c|c|}
\hline \multirow[b]{2}{*}{ Component } & \multicolumn{3}{|c|}{ Initial Eigenvalues } & \multicolumn{3}{|c|}{$\begin{array}{c}\text { Extraction Sums of Squared } \\
\text { Loadings }\end{array}$} \\
\hline & Total & $\begin{array}{c}\% \text { of } \\
\text { Variance }\end{array}$ & $\begin{array}{c}\text { Cumulat } \\
\text { ive } \%\end{array}$ & Total & $\begin{array}{c}\% \text { of } \\
\text { Variance }\end{array}$ & $\begin{array}{c}\text { Cumulative } \\
\%\end{array}$ \\
\hline 1 & 4.894 & 23.303 & 23.303 & 4.894 & 23.303 & 23.303 \\
\hline 2 & 3.510 & 16.715 & 40.018 & 3.510 & 16.715 & 40.018 \\
\hline 3 & 2.403 & 11.441 & 51.459 & 2.403 & 11.441 & 51.459 \\
\hline 4 & 1.904 & 9.066 & 60.526 & 1.904 & 9.066 & 60.526 \\
\hline
\end{tabular}

The data from table 3 shows, cumulative variances explained by four factors reached the desired level. Based on this table, and analysis of the scree plot, the first four factors are selected for retention.

A varimax rotation was conducted in this stage.

Table: Rotated component matrix

\begin{tabular}{|l|c|l|l|l|}
\hline Variables & Factor 1 & Factor 2 & Factor 3 & Factor 4 \\
\hline Mental Refreshment & .787 & & & \\
\hline Body Fitness & .781 & & & \\
\hline Adventuresome & .771 & & & \\
\hline Exercise & .767 & & & \\
\hline Tourism & .731 & & & \\
\hline Sense of Freedom & .716 & & & \\
\hline Less Costly & & .793 & & \\
\hline
\end{tabular}


Asian Business Review, Volume 5, Number 1/2015 (Issue 10)

ISSN 2304-2613 (Print); ISSN 2305-8730 (Online)

\begin{tabular}{|l|l|l|l|l|}
\hline \hline Saves Time & & .775 & & \\
\hline $\begin{array}{c}\text { Protecting the } \\
\text { Environment }\end{array}$ & .735 & & \\
\hline $\begin{array}{c}\text { Saves from Traffic Jam } \\
\text { and Road Hassels }\end{array}$ & & .720 & & \\
\hline Wet and Muddy Roads & & & .881 & \\
\hline Rain & & & .859 & \\
\hline Too Hot or too Cold & & & .739 & \\
\hline Lack of safe space & & & & .883 \\
\hline $\begin{array}{l}\text { Disobedience of Traffic } \\
\text { Rules }\end{array}$ & & & & .863 \\
\hline
\end{tabular}

Factors can be classified into four categories from the highest loading variables. Factor one and two represents favorable factors towards cycling while factor three and four specify unfavorable factors regarding cycling. Four factors can be named as follows:

Table 5: factors and variables

\begin{tabular}{|c|l|l|}
\hline $\begin{array}{c}\text { Factors } \\
\text { Number }\end{array}$ & Factor Name & Name of Variables \\
\hline 1 & Health & $\begin{array}{l}\text { Mental Refreshment, Body } \\
\text { Fitness, Adventuresome, Exercise, } \\
\text { Tourism, Sense of Freedom }\end{array}$ \\
\hline 2 & Convenience & $\begin{array}{l}\text { Least Costly, Saves Time, } \\
\text { Protecting the Environment, Saves } \\
\text { from Traffic Jam and Road Hassel }\end{array}$ \\
\hline 3 & Weather & $\begin{array}{l}\text { Wet and Muddy Roads, Rain, Too } \\
\text { Hot or Too Cold }\end{array}$ \\
\hline 4 & Security & $\begin{array}{l}\text { Lack of Safe Space, Disobedience } \\
\text { of Traffic Rules }\end{array}$ \\
\hline
\end{tabular}

\section{Discussion}

Factor 1-Health: The highest loading variables in this factor are-Mental Refreshment, Body Fitness, Adventuresome, Exercise, Tourism, and Sense of Freedom. These variables are related to the soundness of both body and mind. Therefore, it has been named as Health Factor. Total variance explained by this factor is $22.87 \%$.

Factor 2- Convenience: Variables comprising this factor are- Least Costly, Saves Time, Protecting the Environment, Saves from Traffic Jam and Road Hassel. As maximum variables are related to time and cost issues, the factor has been designated as Convenience factor. $15.81 \%$ variance has been explained by this factor. Factor 3- Weather: This factor explains $11.43 \%$ variance. The variables included here are Wet and Muddy Roads, Rain, Too Hot or Too Cold. This is an unfavorable factor in the study. It shows that the weather situation in this tropical country is troublesome for cyclist.

Factor 4- Security: This factor is comprised of only two variables namely Lack of Safe Space, Disobedience of Traffic Rules. Lack of safer place for parking the bicycle and chaotic road environment create insecurity among the cyclists for which the factor is named after security. Variance explained by this factor is $10.42 \%$.

\section{CONCLUSION}

Bangladesh holds a well reputed position in the world in exporting quality bicycles. Few years ago, it was the $7^{\text {th }}$ largest exporter in the world (Alam, 2013). The bicycle revolution in the country encouraged many young entrepreneurs to set up new ventures based on bicycles and their accessories. To flourish this domestic market as well as grabbing a hold in the international market, bicycle marketer should concentrate more on understanding the bike customers. Proper segmentation can help the marketers meeting the demand of target market and satisfying them with quality features.

The study result illustrates Health and Convenience is the major motivating factors in bicycling. The number of cyclists is growing at a faster rate all over the country. Findings show that, bicycle users hardly use private cars, motor bikes and other large fuel dependent vehicles. If this trend continues, soon bicycle can replace these public transports like Copenhagen and Amsterdam. But few considerations have to be made to ensure road safety for the cyclists. Study indicates respondents encounter problems regarding security issues. Necessary amendments should be made to maximize safety for the bicyclists on the road.

Countries within the Asian continent exhibit similarities in demographic and economic structures. Moreover, increasing level of pollution is a big concern for these countries. Governments of these countries can jointly formulate a common strategy to promote bicycling to minimize the number of problems the countries are facing at present. Moreover, use of bicycle reduces the amount of carbon emission on the road. Bangladesh lies in the risk zone to experience the devastating consequences of climate change. By adopting this eco-friendly vehicle, Bangladesh can create a benchmark for other countries and raise a strong voice in the international community in the issue of climate change. Bicycling culture introduced a new arena in the field of recreation. It can be used to direct the young generation from getting engage with idle activities and turning their leisure time into a more productive one. To make this happen, initiatives should be taken from individual and social sections as well as from government. Appropriate policy design and marketing strategy should be developed to expand the usage of this environment friendly vehicle for greater benefit.

\section{ReCOMmEndations}

Based on the findings, following measures are suggested:

- The findings show that the bicyclists are favorableabout Health factor and convenient factor. The busy lifestyle of people provides low ground tomaintain physical fitness. Besides, Diabetics and heart-diseases are very common and fatal in Bangladesh. Promoting cycling in a larger extent may minimize the risks of these diseases. As cycling saves both time and cost, it influences the level of productivity both individually and collectively. The 
survey result shows that cycling is advancing in Bangladesh with the hand of the young generation, majority of who are students and service holders. Therefore, marketers can tailor services and promotional messages targeting these groups of customers. Meanwhile, extensive research can be conducted to identify specific reasons for lower number of female bicyclists and finding a possible solution to encourage them in cycling.

- The study reveals that bicycle users barely use personal car, motorbike and public transports. Therefore, bicycling can be used to minimize traffic congestion on the busy roads. The enhancing number of bicyclists will reduce the number of large vehicles on the road. Educational institutions and government can work together on this as students are the primary users of bicycle.

- The study also shows, factor loading is high on Security factor. Cyclists are very concerned about security issues on the road. By introducing bike lane as promised, government can create a pave way for safety on the road for the cyclists (Chowdhury, 2014).

- The focus group session revealed that cyclists often experience misbehave from other drivers. As bicycling revolution is comparatively newer concept in Bangladesh, people have less knowledge about road rules for cyclists. Educating the drivers of all vehicles can create a disciplined road experience for all. Also, government can take measures to provide adequate bike parking facilities.

- The hilly tracks and beautiful landscape in Sylhet city render opportunities for the cyclists to explore the scenic beauty of this region. Sylhet is already renowned as a popular tourist destination. Due to the land structure, many of the places can only be accessed through the use of bicycle. The tourism marketers can use bicycling concept and facilitate the tourists to experience wild beauty of Sylhet with this two wheel vehicle.

\section{REFERENCES}

Ahmed, M. (2015). The Role of Self-esteem and Optimism in Job Satisfaction among Teachers of Private Universities in Bangladesh. Asian Business Review, 1(2), 114-120. Retrieved fromhttp://journals.abc.us.org/index.php/abr/article/vie $\mathrm{w} / 2.5$ Ahmed

Akter, S. (2015). Empowerment: Doctor vs Nurses. Asian Business Review, 1(2), 136-139. Retrieved from http://journals.abc.us.org/index.php/abr/article/view/2.9Akter

Alam, D. (2013) Riding on Biking in new Business Line. The Financial Express. [Online] 24 ${ }^{\text {th }}$ December. Available from: http://www.thefinancialexpress-

bd.com/2013/12/24/10376/print [Accessed: $15^{\text {th }}$ January 2015]

Alam, S. (2015). Factors Affecting Job Satisfaction, Motivation and Turnover Rate of Medical Promotion Officer (MPO) in Pharmaceutical Industry: A Study Based in Khulna City. Asian Business Review, 1(2), 126-131. Retrieved from http://journals.abc.us.org/index.php/abr/article/vi ew/2.7Alam
Bdcyclists. (2014) [Online] Available from: http:/ / bdcyclists.com/home/about/read-first/ [Accessed: $15^{\text {th }}$ November 2014]

Chowdhury, S. T. (2014) Revolution on two wheels gets Dhaka moving. Al Jazeera News. [Online] $8^{\text {th }}$ April. Available from: http://www.aljazeera.com/indepth/features/2014/04/re volution-two-wheels-gets-dhaka-moving20144883859484665.html [Accessed: 10 $0^{\text {th }}$ March 2015]

Dekoster, J.and Schollaert, U. (1999)Cycling: the way ahead for towns and cities. Luxembourg: Office for Official Publications of the European Communities. [Online] Available from: http://ec.europa.eu/environment/archives/cycling/cycli ng_en.pdf [Accessed: $4^{\text {th }}$ November 2014]

Enabling Change. (2011) what enables cycling and safe cycling behaviours? [Online] Available from: http://www.enablingchange.com.au/tools.html [Accessed: $4^{\text {th }}$ November 2014]

Hossain, M., \& Siddique, T. (2015). Career Preference of Business Graduate in Bangladesh: A Case Study of Some Selected Private Universities. Asian Business Review, 1(2), 106-113. Retrieved from http://journals.abc.us.org/index.php/abr/article/view/2 .4Hossain

Malhotra, N.K. and Dash, S. (2010) Marketing Research: An Applied Orientation. $6^{\text {th }}$ Ed.India: Pearson Education. P-586

Mohaimen, M. (2015). Talent Management: Three new Perceptions intended for managing and retaining Talent in Bangladesh. Asian Business Review, 3(3), 07-15. Retrieved fromhttp://journals.abc.us.org/index.php/abr/article/vie $\mathrm{w} /$ Mohaimen

Rahman, M., \& Islam, M. (2012). An Analytical Study on Determining Effective Factors for Recruiting Right Person. ABC Journal Of Advanced Research, 1(2), 50-56. Retrieved from http://journals.abc.us.org/index.php/abcjar/article/view/2.6

Saelens, B. E. , Sallis, J. F. and Frank, L. D. (2003) Environment correlates of Walking and Cycling: Findings from the transportation, urban designs and planning literatures. Annals of Behavioral Medicine. [Online] 25 (2). pp. 80-91. Available

from: http:/ /link.springer.com/article/10.1207\%2FS15324796AB M2502_03 [Accessed: 18 ${ }^{\text {th }}$ September 2014]

Schiffman, Leon.G. and Kanuk, Leslie. L (2004) Consumer Behaviour. $8^{\text {th }}$ Ed. New Jersey: Prentice Hall. pp 87-113.

Sener, I. N. , Eluru, N. and Bhat, C.R.(2009) An Analysis of Bicyclists and Bicycling Characteristics: Who, Why, and How Much are they Bicycling? Transportation Research Record. [Online] 2134. pp.63-72. Available from:http:/ / repositories.lib.utexas.edu/handle/2152/2381 0 ? show =full [Accessed: $4^{\text {th }}$ November 2014]

Sustian Cyclists. (2015) [Online] Available from: https://www.facebook.com/groups/Sustiancyclist/ [Accessed: 19th March 2015]

Sylhet Cycling Community. (2015) [Online] Available from: https://www.facebook.com/groups/cyclomania.sylhet [Accessed: 19 ${ }^{\text {th }}$ March 2015]

UCI. (2014) Copenhagen, the most bicycle-friendly city in the world. [Online] Available from: http:/ / www.uci.ch/cyclingforall/copenhagen-the-mostbicycle-friendly-city-the-world/ [Accessed: 19 ${ }^{\text {th }}$ March 2015]

$$
\text { - } 0 \text {-- }
$$

